Academic Platform Journal of Engineering and Science

\title{
Kopula Yöntemi ile Osmaniye Bölgesinin İki Değişkenli Kuraklık Frekans Analizi
}

\author{
${ }^{1,2}$ Musa Eşit, ${ }^{2}$ Mehmet İshak Yüce \\ ${ }^{1}$ Gaziantep Üniversitesi İnşaat Mühendisliği Bölümü, Gaziantep, yuce@gantep.edu.tr, \\ ${ }^{2}$ Adıyaman Üniversitesi İnşaat Mühendisliği Bölümü, Adıyaman, mesit@adiyaman.edu.tr,
}

Research Paper

Arrival Date: 29.04.2020

Accepted Date: 06.06.2021

\begin{abstract}
$\ddot{O} \mathbf{z}$
İklim değişikliğinin dünyanın birçok bölgesinde ekstrem doğa olaylarını tetiklediği gerçeği, birçok bilim insanı tarafindan ciddi bir vaka olarak kabul edilmektedir. Çok değişkenli frekans dağılımları, hidrolojik tasarım ve risk yönetimi için giderek daha fazla önem kazanmaktadır. Geleneksel çok değişkenli dağılımlar, tüm bileşen marjinallerinin aynı dağılım ailesinden olması gerektiği için ciddi şekilde sınırlamalara sahiptir. Kopula yöntemi, bu sınırlamanın üstesinden gelen çok değişkenli dağılımların türetilmesi için yeni ortaya çıkan bir yaklaşımdır. Bu çalışmada, Osmaniye ilinin yağış istasyonu uzun dönem veriler ile kuraklık analizi kopula fonksiyonu kullanılarak hesaplanmıştır. İlk olarak, kuraklık parametreleri olan kuraklık süresi ve şiddeti SPI metodu kullanılarak elde edilmiştir. Gözlemlenen kuraklık süresi için Lognormal, kuraklık şiddeti için ise Weibull en uygun marjinal dağılım olarak bulunmuştur. Her bir kuraklık parametresi için tek değişkenli dağılım fonksiyonu elde edildikten sonra, Gumbel kopulası belirlenen 10 kopula fonksiyonu arasında Akaike Bilgi Kriteri (AIC), Bayes Bilgi Kriteri (BIC), Maksimum olabilirlik (MLE) yöntemleri ve kuyruk bağımlılığı da dikkate alınarak seçilmiştir. En son olarak Osmaniye ili kuraklık olaylarının süre ve şiddet parametrelerinin ortak dönüş periyotları hesaplanmıştır. Bu analiz sonucunda, karar vericilere Osmaniye ilinin gelecekteki kuraklıklara daha duyarlı olması konusunda bilgi verebilir. Bu bilgiler ışığında, muhtemel yapılması düşünülen su temini sistemi, hidrolik tasarım ve su yönetimi gibi konularda yararlı bilgiler sağlamaktadır.
\end{abstract}

Anahtar Kelimeler: SPI, Kopula, Osmaniye, Yağış, Dönüş periyodu

\section{Bivariate Drought Frequency Analysis based on Copula Theory for Osmaniye Region}

\author{
${ }^{1,2}$ Musa Eşit, ${ }^{2}$ Mehmet İshak Yüce \\ ${ }^{1}$ Gaziantep University, Department of Civil Enginnering, Gaziantep, yuce @ gantep.edu.tr \\ ${ }^{2}$ Adıyaman University, Department of Civil Enginnering, Adıyaman, mesit@adiyaman.edu.tr
}

\begin{abstract}
Multivariate frequency distributions are becoming increasingly important for hydrological design and risk management. Traditional multivariate distributions have serious limitations as all component margins should be from the same distribution family. The Copula function is a newly approach to deriving multivariate distributions that overcome this limitation. In this study, drought analysis was calculated using the copula function for Osmaniye province with long-term precipitation data. Firstly, drought parameters including drought duration and severity were obtained by using SPI method. Lognormal and Weibull was observed to be the most suitable marginal distribution for drought duration and drought severity, respectively. After obtaining the univariate distribution function for each drought parameter, the Gumbel copula was selected among the 10 copula functions considering Akaike Information Criterion (AIC), Bayes Information Criterion (BIC), Maximum likelihood (MLE) methods and tail dependency. Finally, the drought return period for Osmaniye province has been calculated. It provides useful information on topics such as the possible water supply system, hydraulic design and water management.
\end{abstract}

Keywords: SPI, Copula, Osmaniye, Precipitation, Return Period 


\section{GíRiş}

Kuraklık, önemli çevresel ve ekonomik etkileri olan büyük doğa tahribatlarından biri olarak görülmektedir. Çöllerden veya ormanlardan bağımsız olarak dünyanın her yerinde herhangi bir iklimde ortaya çıkabilir. Aynı zamanda en pahalı ama en az anlaşılmış doğal tehlikelerden biri olarak algılanmış olup [1], tarımsal, ekonomik ve çevresel zararlar üzerinde büyük olumsuz etkilere neden olabilir [2,3]. Son yıllarda, dikkate değer nüfus artışı ve iklim değişikliğinin neden olduğu yağışlardaki düzensizlik nedeniyle kuraklık sıklığ1 önemli ölçüde artmıştır [4]. Örneğin, eski dönemdeki kuraklıklar büyük nüfusları etkilemiş olup (doğal afetlerle kıyasla \%35'ini temsil etmektedir), bu da genellikle önemli ölçüde ölümler ile sonuçlanmıştır [5].

Kuraklık temel olarak dört bileşenle karakterize edilir: Süre, şiddet, yoğunluk ve zaman aralığı. Kuraklıklar karmaşık olgular olduğundan, tek bir değişken tek başına kuraklıkların kapsamlı bir değerlendirmesini sağlamamaktadır [7]. Bu nedenle, tek değişkenli kuraklık özelliklerine dayanan bir analiz, kuraklık bileşenleri arasında anlamlı bir ilişki yakalayamaz. Kuraklıkları tespit etmek ve izlemek için çeşitli endeksler geliştirilmiş olup, yaygın olarak Palmer Kuraklık Şiddet İndeksi (PDSI) ve Standart Yağış İndeksi (SPI) kuraklık sınıflandırılması için daha sık kullanılan indekslerdir [8]. Su dengesi kavramına dayanan Palmer Kuraklık Endeksi, yağış, buharlaşma, su akışı ve toprak nemi gibi parametreleri kalibre etmeyi içermektedir. Bu indeks Amerika Birleşik Devletleri'nde uygulanmakta olup, ancak başka yerlerde çok az kabul görmektedir [9]. Guttman [10,11], Ray ve Shewale [12]'in yaptıkları çalışma sonuçlarına göre, nemli bölgelerde bu indeksin tarımsal kuraklığı, yarı kurak ve kurak alanlarda ise hidrolojik kuraklığı temsil ettiğini öne sürmüşlerdir.

Standart Yağış İndeksi, olasılık kavramına dayanan ve yaygın olarak kabul edilen bir başka indekstir. Yağış anomalileri, küresel iklimin doğal olarak yinelenen bir özelliği olup ve kuraklık, hidrolojik döngünün çeşitli

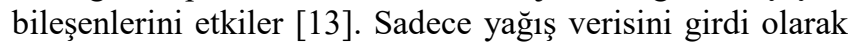
hesaplayan bu indeks, kuruluk ve nemlilik sınıflandırmasında PDSI' dan daha iyi temsil ettiği incelenmiştir [10]. SPI, yağıştan ortalama farkın standart sapmaya bölünmesiyle elde edilen farkı göstermektedir; bu iki istatistiksel parametre, en az 30 yıl önce geçmiş sürekli kayitlardan belirlenmektedir [14,15]. Bu indeksin standartlaştırılmış olmasından dolayı, dünyadaki kuraklık etkisini değerlendirmek için kullanılabilir. Belirli bir konum için SPI, seçilen zaman ölçeği için olasılık dağılım fonksiyonunu tahmin ederek kısa, orta veya uzun vadeli zaman ölçeği için de hesaplanabilir. Bu, daha önce bahsedilen farklı kuraklık kategorilerinin etkisini ele almak için yararlı bir indeks olarak değerlendirilmektedir $[16,17,18]$.

Kuraklık genellikle süre, şiddet, pik değer ve benzeri gibi ilişkili birkaç değişkenle karakterize edilebilen karmaşık bir olgudur [19]. Kuraklık özelliklerini (örn. frekans, risk, tehlike vb.), nicel olarak değerlendirmek için en uygun yol olasılık teorisi ve stokastik yöntemini kullanmaktır [20]. Kuraklıkların olasılıksal karakterizasyonu hakkında önemli ölçüde araştırma yapılmıştır. Bununla birlikte, bu çalışmaların çoğunluğu tek değiş̧kenli analizle uğraşmış olup, kuraklık birkaç rastgele ilişkili değişkenle karakterize edilen karmaşık bir olgu olduğundan, kuraklık özelliklerinin tek değişkenli analizi, değişkenler arasındaki önemli korelasyonu açıklayamamaktadır [21]. Çok değişkenli analizler, kuraklıkların daha kusursuz bir karakterizasyonu sağlamaktadır. Bununla birlikte kuraklık durumlarında, kuralık parametrelerinin (şiddet ve süre vb.) farklı dağılım fonksiyonlarına uyması sebebiyle, çok değişkenli modellerin oluşturulması zordur. Bu nedenle, geleneksel çok değişkenli frekans analizi yöntemlerini uygulayarak, kuraklık özelliklerini tam olarak tanımlamak mümkün değildir [22].

Son on yılda, kopulalar çeşitli disiplinlerde çok değişkenli problemleri ele alma yöntemi olarak ortaya çıkmıştır [23]. Bununla birlikte, kopulaları kullanan çok değişkenli dağılımlar bu tür zorlukların üstesinden gelebilir. Son yıllarda, kopulalar çok değişkenli hidrolojik analiz için kullanılmıştır. Örneğin, yağmur sıklığı analizi [24], taşkın frekans analizi, kuraklık frekans analizi [20] yapılmıştır. Kopula fonksiyonlarının teorik altyapısı hakkında detaylı bilgi Nelson [25] ve Salvadori ve ark. [23] tarafindan araştırılmıştır. Kuraklık frekans analizi için Shiau [20], kuraklık süresi ve şiddetinin ortak dağılımını iki boyutlu kopulalar kullanarak modellemiştir. Mirakbari ve ark. [26] bölgesel kuraklık analizi için iki değişkenli kopula fonksiyonlarını kullanmışlardır. Çok değişkenli kopulaların (iki değişkenden fazla) kullanımı da son zamanlarda ortaya çıkmıştır. Song ve Singh [22] kuraklık süresi, şiddeti ve zaman aralığ 1 arasındaki ortak olasılık dağılımını üç değişkenli Plackett kopula fonksiyonunu kullanarak modellemiştir. Geniş bir bağımlılı̆̆ karakterize edebilen çeşitli kopulalar bulunduğundan, farklı hidrolojik uygulamalar için uygun kopulaların seçimi kolay olmamaktadir.

Literatürde çok sayıda kopula temelli kuraklık çalışması bulunabilse de sadece birkaç araştırmacı Türkiye'de çok değişkenli kuraklık modellemesi için kopula fonksiyonlarını değerlendirmiştir. Tosunoğlu ve Can [27], 1 aylık Standart Yağış Endeksi'nde (SPI) Arşimet kopulası kullanarak meteorolojik kuraklıkların Türkiye üzerindeki ortak olasılık dağılımlarını modellemek için uygulamışlardır. Bu çalışmanın amacı, Osmaniye bölgesinin çift değişkenli kopula fonksiyonu kullanılarak, meteorolojik kuraklığın ortak olasılık dağılımlarını elde etmektir.

\section{MATERYAL VE METOT}

\subsection{Kuraklık Parametrelerinin Hesaplanması}

Bir SPI serisine dayanan kuraklık tanımlama, kuraklık döneminin, SPI değerlerinin 0'dan küçük olduğu $\operatorname{ard} 1$ şık sayıda zaman aralığı olarak kabul edilmesi ile gerçekleştirilebilir. Şekil 1.'de SPI ve kuraklık 
parametrelerinin zaman serilerini göstermektedir. Her kuraklık olayı kuraklık süresi $\mathrm{D}$, kuraklık şiddeti $\mathrm{S}$ olmak üzere iki ana özellik ile karakterize edilir. Bu değişkenlerin tanımları aşağıda açıklanmıştır:

Kuraklık süresi, D, SPI sıfır eşik değerinin altında kaldığı ardışık aralıkların (ay) sayısı olarak tanımlanır. Kuraklık şiddeti S, kuraklık dönemi boyunca kümülatif bir SPI değeri olarak tanımlanır. Kuraklık şiddeti aşağıdaki formülle hesaplanmaktadir.

$$
\mathrm{S}=-\sum_{\mathrm{i}=1}^{\mathrm{D}} \mathrm{SPI}_{\mathrm{i}}
$$

Kuraklık zaman aralığı L, bir kuraklığın başlamasından bir sonraki kuraklığın başlangıcına kadar geçen süre olarak tanımlanır [8]. Standartlaştırılmış SPI değerlerine dayanarak, kuraklık sinıflandırılması Tablo 1.'de gösterilmiştir.

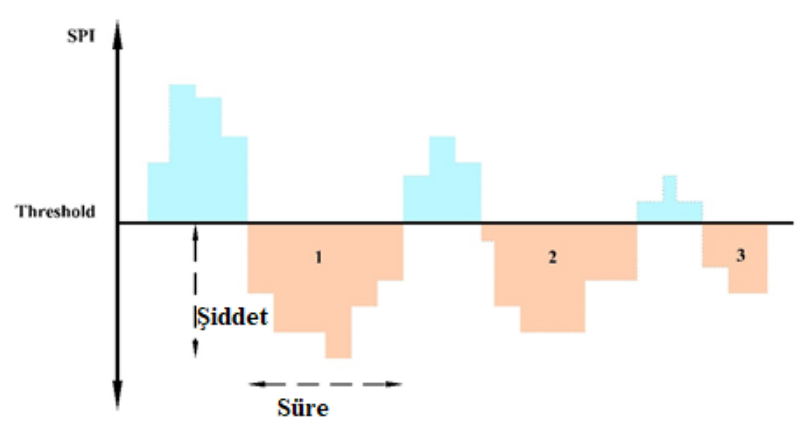

Şekil 1. Kuraklık parametrelerinin grafiksel olarak gösterimi

Tablo 1. SPI metoduna göre indeks değerleri ve siniflandirma

\begin{tabular}{ll}
\hline SPI & Kategori \\
\hline$\geq 2$ & Olağanüstü Nemli \\
$1.50 \sim 1.99$ & Çok Nemli \\
$1.00 \sim 1.49$ & Orta Nemli \\
$0.99 \sim 0$ & Normal \\
$0 \sim-0.99$ & Normal Kurak \\
$-1.00 \sim-1.49$ & Orta Kurak \\
$-1.50 \sim-1.99$ & Şiddetli Kurak \\
$\leq-2$ & Olağanüstü Kurak \\
\hline
\end{tabular}

\subsection{Tek Değişkenli Kuraklık Parametrelerinin Dağılımı}

İki değişkenli kuraklık frekans analizini yapmadan önce, öncelikle her bir kuraklık parametresi için (süre ve şiddet) en uygun dağılımın bulunması gereklidir. Önceki yapılan birçok çalışmada kuraklık süresi üstel dağılım [20,28] ile, kuraklık şiddeti Gama dağılımı [20,29] ile daha iyi modellendiği gösterilmiştir. Ancak, Yusof ve ark., [30] en çok kullanılan iki olasılık dağılımının her durumda iyi olmadığını ileri sürmektedir. $\mathrm{Bu}$ nedenle, bu çalışmada kuraklık şiddetine ve kuraklık süresine en iyi dağılımı bulmak için, literatürde en çok kullanılan Lognormal, Lojistik, Gama, Üstel, Weibull ve Normal dağılımlar gibi çeşitli dağılımlar kullanılmıştır. Her kuraklık parametresi için kullanılan dağılımların performansı Anderson-Darling (AD), Kolmogorov Smirnov (KS), Cramers-von Mises (CvM), Akaike Bilgi Kriteri (AIC), Bayes Bilgi Kriteri (BIC) ve Maksimum olabilirlik yöntemleri (MLE) ile test edilmiştir.

\subsection{Kopula Teorisi}

Kopula, rastgele değişkenler arasındaki bağımlılık yapısını modelleyen kullanışlı bir fonksiyondur. Yani, bir kopula, rastgele değişkenlerin ortak olasılık dağılımlarını, rastgele değişkenlerin marjinal dağılımlarını birleştirerek oluşturmaktadır [31,32]. Birçok kopula fonksiyonu olmasına karşın, Arşimet kopula fonksiyonları genel olarak hidrolojik ve meteorolojik alanlarda kullanılmaktadır. Sklar teoremine göre, iki rasgele değişken $\mathrm{x}$ ve y sırasıyla marjinal dağılım fonksiyonu $\mathrm{FX}(\mathrm{x})$ ve $\mathrm{FY}(\mathrm{y})$ olarak düşünülürse, bu iki farklı marjinali birbirine bağlamak için modellenen FX,Y (x, y) benzersiz bir kopula $\mathrm{C}$ vardır. $\mathrm{C}$ aşağıdaki formülle matematiksel olarak ifade edilir;

$\mathrm{F}_{\mathrm{X}, \mathrm{Y}}(\mathrm{x}, \mathrm{y})=\mathrm{C}\left(\mathrm{F}_{\mathrm{X}}(\mathrm{x}), \mathrm{F}_{\mathrm{Y}}(\mathrm{y})\right)$

Denklem 1'de görüldüğü gibi, bir kopula tek değişkenli bir dağılıma göre çok değişkenli bir dağılım ile tanımlanabilmektedir. İlaveten, FX (x) ve FY (y) sürekli ise, C tamamen benzersiz olup [7], ortak olasılık yoğunluk fonksiyonu aşağıdaki gibi tanımlanmaktadır;

$f_{X, Y}(x, y)=c\left(F_{X}(x), F_{Y}(y)\right) f_{X}(x) f_{Y}(y)$

Burada, fX (x) ve fY (y), sırasıyla FX (x) ve FY (y) ile ilişkili yoğunluk fonksiyonlarıdır ve c, C'nin yoğunluk fonksiyonu olarak ifade edilir.

$\mathrm{c}(\mathrm{u}, \mathrm{v})=\frac{\partial^{2} \mathrm{C}(\mathrm{u}, \mathrm{v})}{\partial \mathrm{u} \partial \mathrm{v}}$

$\mathrm{Bu}$ kopula fonksiyonlarının yapısı ve parametreleri detaylı olarak Tablo 2'de kısaca verilmiştir. 
Tablo 2. Kopula fonksiyonlarının genel tanımı

\begin{tabular}{|c|c|c|}
\hline Copula & Function & Support \\
\hline Gaussian copula & $\mathrm{C}\left(u_{1}, u_{2}\right)=\int_{-\infty}^{\phi-1}\left(u_{2}\right) \int_{-\infty}^{\phi-1}\left(u_{1}\right) \frac{1}{2 \pi\left(1-p^{2}\right)^{\frac{1}{2}}} \exp \left\{-\frac{x_{1}^{2}+x_{2}^{2}-2 p x_{1} x_{2}}{2\left(1-p^{2}\right)}\right\} \mathrm{d} x_{1} x_{2}$ & $x_{1}, x_{2} \in \mathrm{R}$ \\
\hline Student t copula (t-copula) & $\mathrm{C}\left(u_{1}, u_{2}\right)=\int_{-\infty}^{t_{v}^{-1}}\left(u_{2}\right) \int_{-\infty}^{t_{v}^{-1}}\left(u_{1}\right) \frac{1}{2 \pi\left(1-p^{2}\right)^{\frac{1}{2}}} \exp \left\{1+\frac{x_{1}^{2}+x_{2}^{2}-2 p x_{1} x_{2}}{v\left(1-p^{2}\right)}\right\}^{-\frac{(v+2)}{2}} \mathrm{~d} x_{1} x_{2}$ & $x_{1}, x_{2} \in \mathrm{R}$ \\
\hline Clayton copula & $\mathrm{C}\left(u_{1}, u_{2}\right)=\left(u_{1}^{-\theta}+u_{2}^{-\theta}-1\right)^{-\frac{1}{\theta}}$ & $\theta \in[0, \theta)$ \\
\hline Gumbel copula & $C\left(u_{1}, u_{2}\right)=\exp \left\{-\left[\left(-\ln u_{1}\right)^{\theta}+\left(-\ln u_{2}\right)^{\theta}\right]^{\frac{1}{\theta}}\right\}$ & $\theta \in[1, \infty)$ \\
\hline Frank copula & $C\left(u_{1}, u_{2}\right)=-\frac{1}{\theta} \ln \left[1+\frac{\left(e^{\left.-\theta u_{1}-1\right)\left(e^{-\theta u_{2}}-1\right)}\right.}{e^{-\theta}-1}\right]$ & $\theta \in \mathrm{R}$ \\
\hline Joe copula & $\mathrm{C}\left(u_{1}, u_{2}\right)=1-\left[\left(1-u_{1}\right)^{\theta}+\left(1-u_{2}\right)^{\theta}-\left(1-u_{1}\right)^{\theta}\left(1-u_{2}\right)^{\theta}\right]^{\frac{1}{\theta}}$ & $\theta \in[0, \theta)$ \\
\hline BB1 copula & $\mathrm{C}\left(u_{1}, u_{2}\right)=\left\{1+\left[\left(u_{1}^{-\theta}-1\right)^{\delta}+\left(u_{2}^{-\theta}-1\right)^{\delta}\right]^{-\frac{1}{\theta}}\right\}$ & $\theta>0, \delta \geq 1$ \\
\hline BB6 copula & $\mathrm{C}\left(u_{1}, u_{2}\right)=1-\left(1-\exp \left\{-\left[\left(-\log \left(1-\left(1-u_{1}\right)^{\theta}\right)\right)^{\delta}+\left(1-\log \left(1-\left(1-u_{2}\right)^{\theta}\right)\right)^{\delta}\right]^{\frac{1}{\delta}}\right\}\right)^{\frac{1}{\theta}}$ & $\theta \geq 1, \delta \geq 1$ \\
\hline BB7 copula & $\mathrm{C}\left(u_{1}, u_{2}\right)=1-\left(1-\left[\left(1-\left(1-u_{1}\right)^{\theta}\right)^{-\delta}+\left(1-\left(1-u_{2}\right)^{\theta}\right)^{-\delta}-1\right]^{-\frac{1}{\delta}}\right)^{\frac{1}{\theta}}$ & $\theta \geq 1, \delta>0$ \\
\hline BB8 copula & $\mathrm{C}\left(u_{1}, u_{2}\right)=\delta^{-1}\left(1-\left\{1-\frac{\left[1-\left(1-\delta u_{1}\right) \theta\right]\left[1-\left(1-\delta u_{2}\right)^{\theta}\right]}{1-(1-\delta)^{\theta}}\right\}^{\frac{1}{\theta}}\right)$ & $\theta \geq 1, \delta \in(0,1]$ \\
\hline
\end{tabular}

\subsection{Kuyruk Bağımlılığı Parametrelerinin Tahmini}

Kuyruk bağımlılığı değişkenlerin sağ üst kuyruğundaki aşırı değerler ve / veya sol alt kuyruğu arasındaki uyumla ilgilidir [34]. Çünkü uzun süreli ve büyük şiddette kuraklık olayı insan toplumu ve ekolojik sistemler üzerinde muazzam bir etkiye sahip olabilir. Üst kuyruk bağımlılığının aşırı kuraklık olayının analizinde alt kuyruk bağımlılığından daha fazla ilgisi olduğu görülmüştür [29]. Hidrolojide, kuyruk bağımlılıklarını göz ardı etmek aşırı kuraklık olayları tahminlerde yüksek belirsizliğe neden olup, bu da hidrolojik tasarım için istenmeyen bulgular ile sonuçlanabilir. Üst (alt) kuyruk bağımlılı̆̆ı, kopula fonksiyonu olarak şu şekilde ifade edilebilir:

$$
\begin{aligned}
& \lambda_{\mathrm{u}}=\lim _{\mathrm{t} \rightarrow 1^{-}} \frac{1-2 t+C(\mathrm{t}, \mathrm{t})}{1-\mathrm{t}} \\
& \lambda_{\mathrm{L}}=\lim _{\mathrm{t} \rightarrow 1^{-}} \frac{\mathrm{C}(\mathrm{t}, \mathrm{t})}{\mathrm{t}}
\end{aligned}
$$

Parametrik olmayan üst kuyruk bağımlılığı aşağıdaki formülle hesaplanabilir.

\subsection{Dönüş Aralı̆̆ı Metodu}

Su kaynakları sistemi, hidrolojik ve hidrolik sistemlerin yönetimine genel bir yaklaşım kuraklık özelliklerinin dönüş aralıklarının tahmin edilmesidir. Özellikle kuraklık koşullarında önemli bilgiler vermektedir. Belirli bir değere eşit veya bu değerden büyük olan tek değişkenlikteki kuraklık süresinin dönüş periyodu şu şekilde hesaplanabilir:

$$
\begin{gathered}
\lambda_{\mathrm{u}}^{\mathrm{CFG}}=2-2 \exp \left\{\frac{1}{\mathrm{n}} \sum_{\mathrm{i}=1}^{\mathrm{n}} \log \left[\frac{\left.\sqrt{\log \left(\frac{1}{\mathrm{u}_{1}}\right) \log \left(\frac{1}{v_{1}}\right)}\right]}{\log \left(\frac{1}{\max \left(\mathrm{u}_{1}, \mathrm{v}_{1}\right)^{2}}\right)}\right]\right\} \\
\mathrm{T}_{\mathrm{D}}=\frac{\mathrm{E}(\mathrm{L})}{1-\mathrm{F}_{\mathrm{D}}(\mathrm{d})}
\end{gathered}
$$

Burada, L kuraklık zaman aralığını göstermektedir. Kuraklık şiddetinin belirli bir değere eşit veya bu değerden büyük dönüş periyodu, aşağıdaki gibi tanımlanan formül kullanılarak elde edilebilir.

$$
\mathrm{T}_{\mathrm{S}}=\frac{\mathrm{E}(\mathrm{L})}{1-\mathrm{F}_{\mathrm{S}}(\mathrm{s})}
$$

Ortak dönüş periyodu kuraklık süresi ve şiddeti için iki koşul için tahmin edilebilmektedir;

$$
\begin{aligned}
& \mathrm{T}_{\mathrm{DS}}=\frac{\mathrm{E}(\mathrm{L})}{\mathrm{P}(\mathrm{D} \geq \mathrm{d}, \mathrm{S} \geq \mathrm{s})}=\frac{\mathrm{E}(\mathrm{L})}{1-\mathrm{F}_{\mathrm{D}}(\mathrm{d})-\mathrm{F}_{\mathrm{S}}(\mathrm{s})+\mathrm{C}\left(\mathrm{F}_{\mathrm{D}}(\mathrm{d}), \mathrm{F}_{\mathrm{S}}(\mathrm{s})\right)}=\frac{\mathrm{E}(\mathrm{L})}{1-\mathrm{F}_{\mathrm{D}}(\mathrm{d})-\mathrm{F}_{S}(\mathrm{~s})+\mathrm{F}_{\mathrm{DS}}(\mathrm{d}, \mathrm{s})} \\
& \mathrm{T}^{\prime}{ }_{\mathrm{DS}}=\frac{\mathrm{E}(\mathrm{L})}{\mathrm{P}(\mathrm{D} \geq \mathrm{d} \text { or } \mathrm{S} \geq \mathrm{s})}=\frac{\mathrm{E}(\mathrm{L})}{1-\mathrm{F}_{\mathrm{DS}}(\mathrm{d}, \mathrm{s})}=\frac{\mathrm{E}(\mathrm{L})}{1-\mathrm{C}\left(\mathrm{F}_{\mathrm{D}}(\mathrm{d}), \mathrm{F}_{\mathrm{S}}(\mathrm{s})\right)}
\end{aligned}
$$


$\mathrm{Bu}$ eşitliklerde, $\mathrm{T}_{\mathrm{DS}}$, hem kuraklık sürenin hem de şiddetinin belirli bir değere eşit veya büyük olması durumunu gösterirken $\left(\mathrm{D} \geq \mathrm{d}\right.$ ve $\mathrm{S} \geq \mathrm{s}$ ), $\mathrm{T}_{\mathrm{DS}}^{\prime}$ dönüş periyodu ise ya kuraklık süresinin ya da kuraklık şiddetinin belirli bir değere eşit veya yüksek olma durumunu ifade etmektedir ( $D \geq d$ ya da $S \geq s$ ).

\section{SONUÇLAR VE TARTIŞMA}

\subsection{Kuraklık Parametrelerinin Marjinal Dağılımı}

İlk olarak, Osmaniye ilinin 1986-2016 yılları arasındaki yağış verilerini kullanarak kuraklık süresi ve şiddeti SPI-3 aylık zaman ölçeğinde metodu ile belirlenmiştir. SPI-3 zaman serisi Şekil 2'de gösterilmiştir.

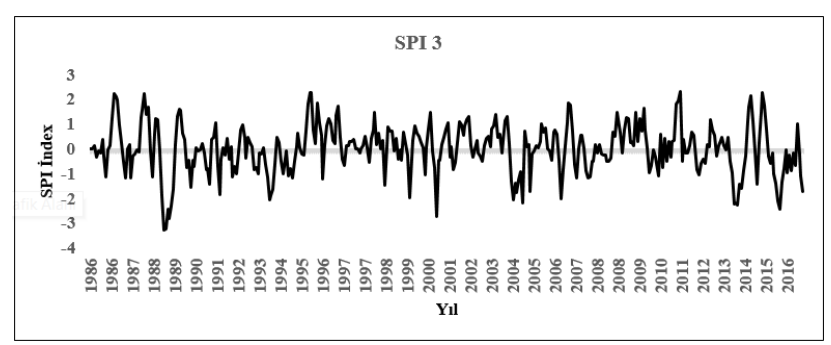

Şekil 2. Osmaniye ilinin SPI-3 aylık zaman serisi

SPI-3 zaman serisinden kuraklık süresi (D), şiddeti (S) ve her bir kuraklığın zaman aralığı (bölüm 2.1'de kuraklık süresinin ve şiddetinin nasıl hesaplanacağ detaylı olarak anlatılmıştır.) belirlendikten sonra, kuraklık parametrelerinin tek değişkenli en uygun marjinal dağılımı Tablo 3 ve 4'teki performans test sonuçlarına hesaplanmıştır. Marjinal dağılımların parametreleri, oluşturulan teorik kümülatif olasılık dağılımlarının, gözlemlenen süre ve şiddetlerin aşılmama ihtimallerine karşı çizilmesiyle ortaya çıkan değerler arasında, en uygun dağılım elde edilmiştir. Seyhan Havzası'nda yer alan meteorolojik istasyonlarda 1986-2016 yılları arası gözlemlenen kuraklık olaylarının süre ve şiddet parametrelerine en uygun teorik dağılımlar Lognormal, Gama, Lojistik, Lojistik, Üstel, Weibull ve Normal dağılımları arasından seçilmiştir. Her kuraklık parametresi için kullanılan dağılımların performansı Anderson-Darling (AD), Kolmogorov Smirnov (KS), Cramers-von Mises (CvM), Akaike Bilgi Kriteri (AIC), Bayes Bilgi Kriteri (BIC) ve Maksimum olabilirlik yöntemleri (MLE) ile test edilmiştir. Performans testleri ile belirlenen en küçük değer, hem kuraklık süresi hem de kuraklık şiddeti için en uygun dağılım bulunmaktadır. Test sonuçlarına göre, Kuraklık süresi için en uygun Lognormal dağılımı, $\alpha=$ $0,855, \beta=0,758$ olarak hesaplanırken, kuraklık şiddeti için en uygun dağılım Weibull, $\eta=1,320 \beta=3,470$ olarak belirlenmiştir. Gözlemlenen veri ve belirlenen en uygun dağılımların kümülatif dağılım fonksiyonları arasındaki ilişki kuraklık süresi ve şiddeti için sırasıyla Şekil 3 'te gösterilmiştir.

Tablo 3. Kuraklık süresi için kullanılan dağılımların performans testleri ile ölçülmesi

\begin{tabular}{lllllll}
\hline Kuraklık Süresi & Lognormal & Lojistik & Gama & Üstel & Weibull & Normal \\
\hline Kolmogorov-Smirnov & $\mathbf{0 , 1 7 2 3}$ & 0,2143 & 0,2040 & 0,2707 & 0,2259 & 0,2285 \\
Cramer-von Mises & 0,3163 & 0,3965 & 0,3234 & 0,4370 & $\mathbf{0 , 3 0 2 3}$ & 0,5817 \\
Anderson-Darling & 2,2704 & 2,7322 & 2,1797 & 2,8326 & $\mathbf{2 , 0 2 4 2}$ & 3,3583 \\
Akaike Bilgi Kriteri (AIC) & $\mathbf{2 1 9 , 8 2 8 0}$ & 255,0369 & 226,5729 & 234,4894 & 229,8280 & 263,6649 \\
Bayes Bilgi Kriteri (BIC) & $\mathbf{2 2 3 , 8 0 6 0}$ & 259,0149 & 230,5508 & 236,4784 & 233,7851 & 267,6428 \\
Maksimum Ol. Yöntemi (MLE) & $\mathbf{- 1 0 7 , 9 1 4 0}$ & $-125,5184$ & $-111,2864$ & $-116,2447$ & $-112,9036$ & $-129,8324$ \\
\hline
\end{tabular}

Tablo 4. Kuraklık şiddeti için kullanılan dağılımların performans testleri ile ölçülmesi

\begin{tabular}{lllllll}
\hline Kuraklık Şiddeti & Lognormal & Lojistik & Gama & Üstel & Weibull & Normal \\
\hline Kolmogorov-Smirnov & 0,0922 & 0,2394 & 0,1111 & 0,1907 & $\mathbf{0 , 0 6 7 5}$ & 0,2433 \\
Cramer-von Mises & 0,0607 & 0,5119 & 0,1206 & 0,4391 & $\mathbf{0 , 0 3 4 1 1}$ & 1,1165 \\
Anderson-Darling & 0,4654 & 3,9670 & 0,7725 & 2,5868 & $\mathbf{0 , 2 0 6 3 0}$ & 6,2317 \\
Akaike Bilgi Kriteri (AIC) & 203,4746 & 275,0349 & 205,608 & 208,5667 & $\mathbf{2 0 0 , 8 6 7 8}$ & 294,1332 \\
Bayes Bilgi Kriteri (BIC) & 207,4526 & 279,0128 & 209,586 & 210,5557 & $\mathbf{2 0 4 , 8 4 5 8}$ & 298,1111 \\
Maksimum Ol. Yöntemi (MLE) & $-99,7372$ & $-135,5174$ & $-100,804$ & $-103,2833$ & $\mathbf{- 9 8 , 4 3 3 9 1}$ & $-145,0666$ \\
\hline
\end{tabular}



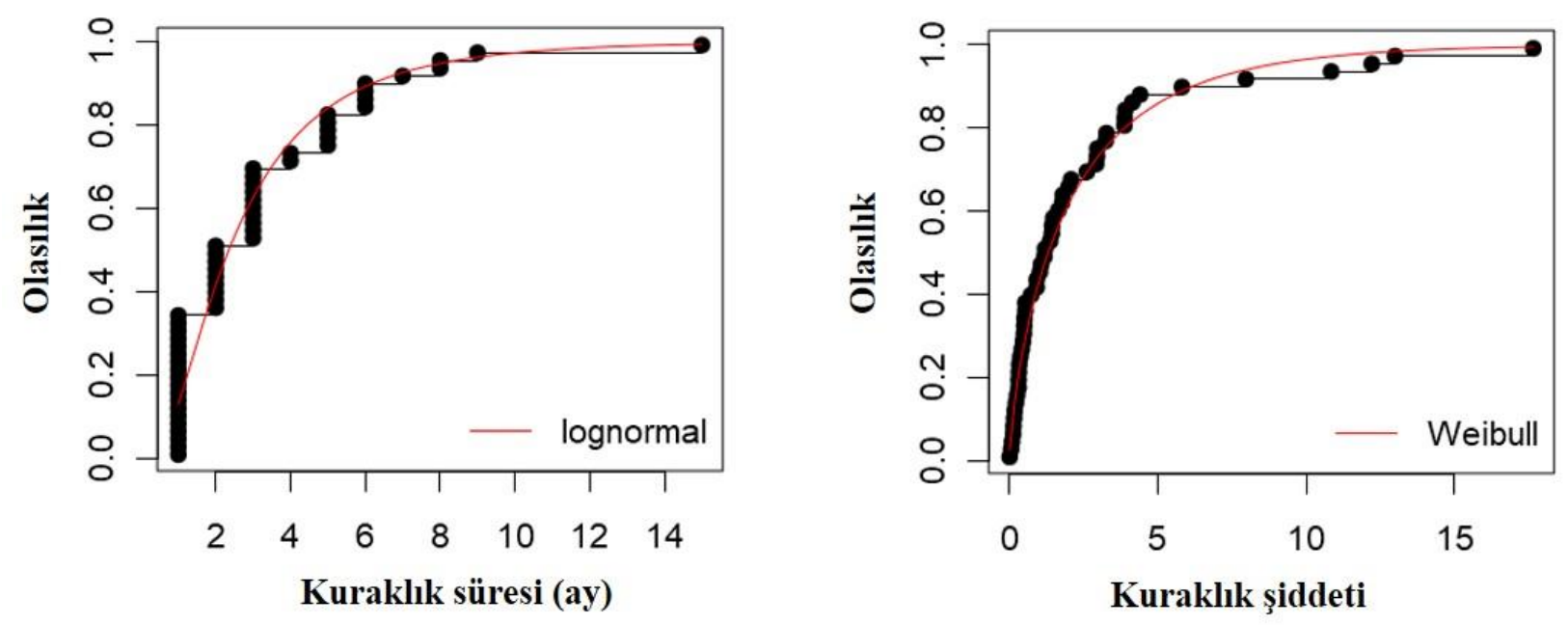

Şekil 3. Kuraklık süresi ve şiddeti için belirlenen en uygun marjinal dağılımların kümülatif dağılım fonksiyonu

\subsection{Ortak Dağılım Fonksiyonun Belirlenmesi}

Gözlemlenen kuraklık süresi ve şiddeti için sırasılya Lognormal ve Weibull en uygun marjinal dağılım olarak hesaplandığı için, genel olarak yaygın kullanılan iki değişkenli dağılımlar kullanılmaz. Bu çalışmada kuraklık süresi ve şiddeti için kopula temelli iki değişkenli dağılım elde edilmiştir. Kuraklık süresi ve şiddeti arasındaki bağımlılığı modellemek için Gaussian, Student't, Clayton, Gumbel, Frank, Joe, BB1, BB6, BB7 ve BB8 kopula dahil olmak üzere 10 kopula test edilmiştir. Gözlemlenen veriler için en uygun kopula; performans testleri, üst kuyruk bağımlılığı dikkate alınmıştır. Bu sonuçlar ışığında, Gumbel kopulası diğer kopula fonksiyonlarına kıyasla en uygun dağılım olarak belirlenmiştir. En düşük AIC ve BIC değerlerinin en uygun kopulayı belirlemede yardımcı olurken, kuraklık süresi ve şiddeti arasındaki bağlılığın, üst kuyruk bağlılığı arasında yakın bir ilişki olması gerekmektedir. Tablo 5'te görüldüğü gibi, gözlemlenen veriler arasındaki veri bağımlılı̆ı Kendall Tau sonucuna göre 0,726 değeri hesaplanırken, bu değere en yakın üst kuyruk bağımlılı̆̆1 sadece Gumbel, Joe, BB6 ve BB7 kopulalarında görülmektedir. $\mathrm{Bu}$ üç kopula arasında en uygun Gumbel kopulası en düşük AIC ve BIC değerine göre hesaplanmıştır. Gumbel kopulası ile üretilen 1000 veri $(u, v)$ ile gözlemlenen veriler arasında iyi bir ilişki Şekil 4'te görülmektedir.

Tablo 5. Kullanılan kopula fonksiyonlarının performans test sonuçları

\begin{tabular}{|c|c|c|c|c|c|c|c|c|c|}
\hline \multirow[b]{2}{*}{ Numara } & \multirow[b]{2}{*}{ Kopula } & \multirow[b]{2}{*}{ MLE } & \multirow[b]{2}{*}{ AIC } & \multirow[b]{2}{*}{$\mathrm{BIC}$} & \multirow[b]{2}{*}{ Par 1} & \multirow[b]{2}{*}{ Par 2} & \multicolumn{2}{|c|}{$\begin{array}{c}\text { Kuyruk } \\
\text { Bağımlılığı }\end{array}$} & \multirow{2}{*}{$\begin{array}{l}\begin{array}{l}\text { Kendal } \\
\text { Tau }\end{array} \\
0.727 \\
\end{array}$} \\
\hline & & & & & & & $\begin{array}{l}\text { Alt } \\
\text { kuyruk }\end{array}$ & $\begin{array}{l}\text { Üst } \\
\text { Kuyruk }\end{array}$ & \\
\hline 1 & Gaussian Kopula & 36,34 & $-70,67$ & $-68,68$ & 0,87 & & 0 & 0 & \\
\hline 2 & Student t Kopula & 36,18 & $-68,35$ & $-64,38$ & 0,86 & 30 & 0,142 & 0,142 & \\
\hline 3 & Clayton Kopula & 24,1 & $-46,21$ & $-44,22$ & 2,2 & & 0,73 & 0 & \\
\hline 4 & Gumbel Kopula & 35,25 & $-68,5$ & $-66,51$ & 2,75 & & & 0,713 & \\
\hline 5 & Frank Kopula & 33,72 & $-65,45$ & $-63,46$ & 9,69 & & 0 & 0 & \\
\hline 6 & Joe Kopula & 32 & $-62,01$ & $-60,02$ & 3,38 & & 0 & 0,772 & \\
\hline 7 & BB1 Kopula & 35,53 & $-67,07$ & $-63,09$ & 0,24 & 2,52 & 0,313 & 0,683 & \\
\hline 8 & BB6 Kopula & 35,25 & $-66,5$ & $-62,52$ & 1 & 2,75 & 0 & 0,714 & \\
\hline 9 & BB7 Kopula & 34,09 & $-64,18$ & $-60,21$ & 2,95 & 1,39 & 0,606 & 0,735 & \\
\hline 10 & BB8 Kopula & 37,96 & $-71,92$ & $-67,94$ & 6 & 0,89 & 0 & 0 & \\
\hline
\end{tabular}

MLE: Maksimum olabilirlik yöntemleri, AIC: Akaike Bilgi Kriteri, BIC: Bayes Bilgi Kriteri, Par: Parametre 


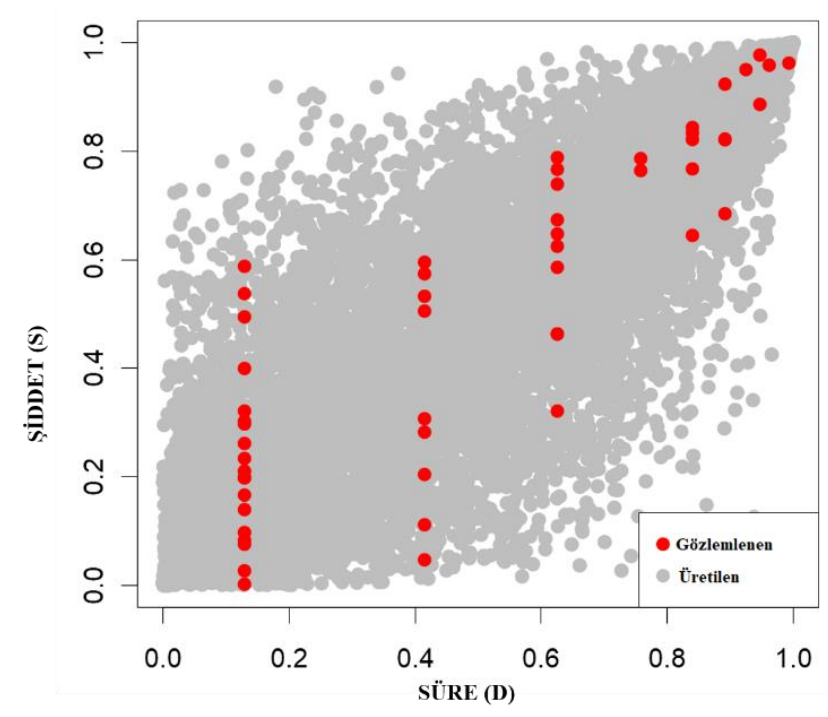

Şekil 4. Gözlemlenen verilerin (kırmızı) Gumbel kopulası ile üretilen rastgele veriler (gri) ile karşılaştırılması

\subsection{Tek ve İki Değişkenli Dönüş Periyodu} Belirlenmesi

Tek değişkenli kuraklık süresi ve şiddeti için belirlenen marjinal dağılımlar için eşitlik 7 ve 8 'deki denklemlere göre belirlenmiştir. $T_{D / S}$ herhangi bir kuraklık parametresinin belirli bir değere eşit veya büyük olması durumundaki dönüş periyodunu $(10,20,50,100,200$ ve 500 yıllık) temsil ederken $\mathrm{E}(\mathrm{L})$ ise kurak geçen ortalama süre aralığını göstermektedir. $\mathrm{E}(\mathrm{L})$ Osmaniye ili için 6.77 ay olarak hesaplanmıştır. Kuraklık süresi ve şiddeti için kendi marjinal dağılımları dikkate alınarak hesaplanan dönüş periyodu Tablo 6'da gösterilmiştir. $\mathrm{Bu}$ sonuçlara göre kuraklık süresi değerlendirildiğinde, kuraklık süresinin 16.07 aya eşit veya yüksek olması durumundaki hesaplanan dönüş periyodu 100 yıl olarak belirlenmiş olup, bu dönüş periyoduna karşllık gelen kuraklık şiddeti ise 17.57 olarak bulunmuştur. Kuraklık süresi ve şiddeti birbirleri arasında yüksek bir bağımlılı̆ga sahip olduklarından, bu parametrelerin tek tek incelenmesinin aksine, ortak değerlendirilmeleri sonucu dönüş periyotlarının hesaplanması, dikkate alınan bölgenin kuraklı̆ğının daha iyi irdelenmesine ve su yönetimi gibi problemlerinin çözümüne fayda sağlayacaktır.

Kopula, kuraklık parametrelerinin ortak dönüş periyotlarını 9. ve 10. eşitliğe göre hesaplamaya imkân sağlamaktadır. $T_{D S}$, hem kuraklık süresinin hem de kuraklık şiddetinin belirli bir değere eşit veya büyük olması durumundaki dönüş periyodunu hesaplarken, $\mathrm{T}^{\prime}{ }_{\text {DS }}$ ise kuraklık süresinin ya da kuraklık şiddetinin belirli bir değere eşit veya yüksek olması durumundaki dönüs periyodunu dikkate almaktadır. Kopula temelli ortak dönüş periyotları Tablo 6'da gösterilmiş̧tir. Örneğin, kuraklık süresinin 16.07 ay ve kuraklık şiddetinin 17.57 eşit veya yüksek olması durumunda, ortak dönüş periyodu $\left(\mathrm{T}_{\mathrm{Ds}}\right) \quad 139$ yıl olarak hesaplanmıştır. Oysaki tek tek kuraklık parametreleri değerlendirildiğinde bu dönüş periyodu $\left(\mathrm{T}_{\mathrm{D} / \mathrm{s}}\right) 100 \mathrm{y} 1 \mathrm{l}$ olarak bulunmuştur. Kuraklık süresinin 16.07 ay ya da kuraklık şiddetinin 17.57 eşit veya yüksek olması durumunda $\left(\mathrm{T}_{\mathrm{DS}}^{\prime}\right)$, ortak dönüş periyodu 77.79 yıl olarak hesaplanmıştır.

Tablo 6. Kuraklık süresi ve şiddetinin ortak dönüş periyotları

\begin{tabular}{lcccc}
\hline $\begin{array}{l}\text { Dönü̈s } \\
\text { Periyodu }\end{array}$ & $\begin{array}{c}\mathbf{D} \\
\text { (Süre) }\end{array}$ & $\begin{array}{c}\mathbf{S} \\
\text { (Şiddet) }\end{array}$ & $\begin{array}{c}\mathbf{T}_{\text {Ds }} \text { (ortak } \\
\text { dönüşs } \\
\text { periyodu) }\end{array}$ & $\begin{array}{c}\mathbf{T}_{\text {'ss }}^{\prime} \text { (ortak } \\
\text { dönüş } \\
\text { periyodu) }\end{array}$ \\
\hline 10 & 7,83 & 8,23 & 13,81 & 7,84 \\
20 & 10,00 & 10,87 & 27,83 & 15,61 \\
50 & 13,27 & 14,60 & 69,88 & 38,93 \\
100 & 16,08 & 17,57 & 139,96 & 77,79 \\
200 & 19,20 & 20,66 & 280,12 & 155,52 \\
500 & 23,86 & 24,91 & 700,60 & 388,71 \\
\hline
\end{tabular}

Kuraklık parametrelerinin ortak dönüş periyotları farklı değerler için hesaplanmış olup, Şekil 5 'te verilmiştir. Bu izohips eğrileri sayesinde, kuraklık parametrelerinin alacağı farklı değerler hesaplanması için olanak sağlamakta olup, ayrıca tek değişkenli frekans analizleri ile kolay bir şekilde kıyaslanabilmektedir. Türetilmiş ortak kuraklık süresi ve şiddeti dönüş periyodu, belirli bir su kaynakları sisteminin kestirilemeyen riskini değerlendirmek için kullanılabilir. Örneğin, su temini sisteminde, kuraklık süresinin 2 ayı kuraklık şiddetinin ise 4'ü aş̧ı̆̆ durumlarda yeterli düzeyde su ihtiyacı karşılayamaz. Böylesi bir durumda ortak dönüş periyodu büyük önem kazanmaktadır. 

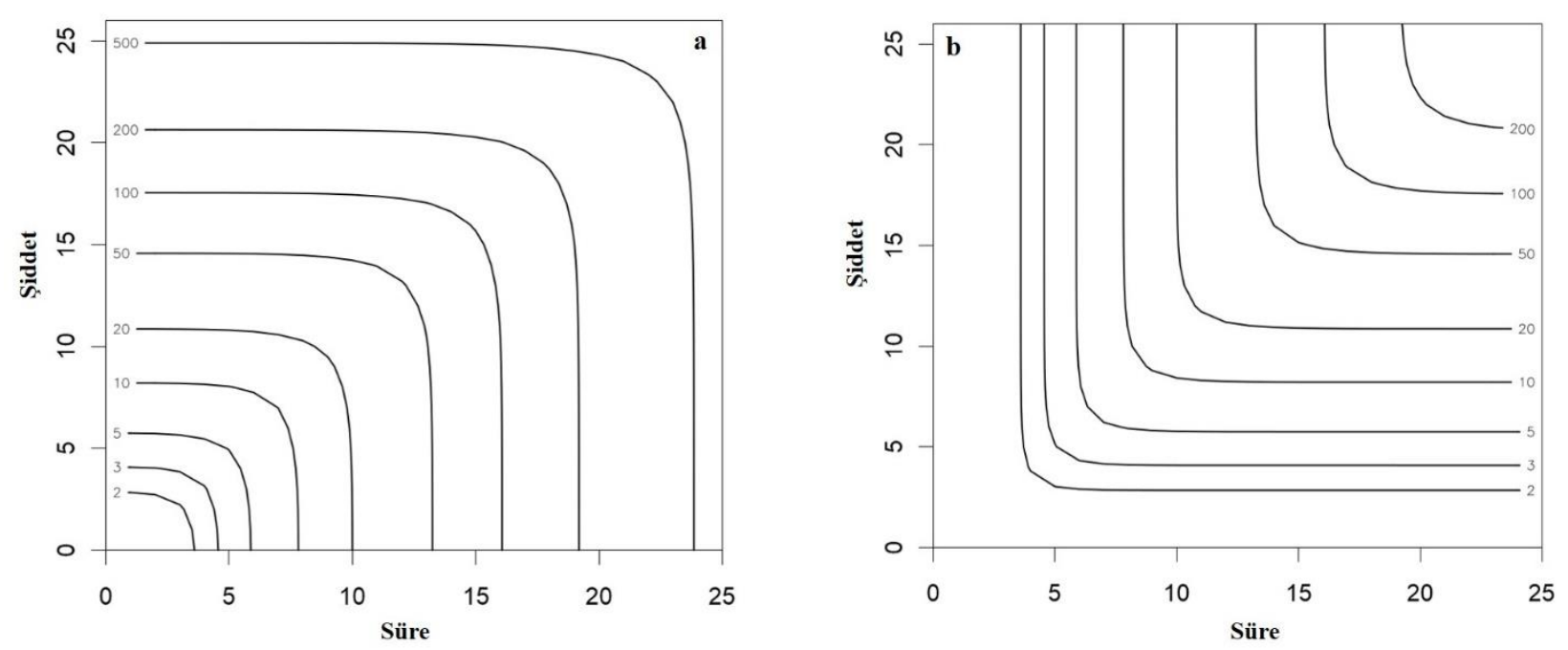

Şekil 5. Kuraklık parametresinin her iki koşul için (a) $\mathrm{T}_{\mathrm{DS}}$ (b) $\mathrm{T}_{\text {DS }}^{\prime}$ ortak dönüş periyotları

\section{KAYNAKLAR}

[1] Kao, S. C., \& Govindaraju, R. S. A copula-based joint deficit index for droughts. Journal of Hydrology, 380(1-2), 121-134, 2010

[2] Heim Jr, R. R. A review of twentieth-century drought indices used in the United States. Bulletin of the American Meteorological Society, 83(8), 1149-1166, 2002

[3] Sheffield, J., Wood, E. F., \& Roderick, M. L. Little change in global drought over the past 60 years. Nature, 491(7424), 435-438, 2012

[4] McKee, T. B., Doesken, N. J., \& Kleist, J. The relationship of drought frequency and duration to time scales. In Proceedings of the 8th Conference on Applied Climatology (Vol. 17, No. 22, pp. 179-183), January 1993

[5] Below, R., Grover-Kopec, E., \& Dilley, M. Documenting drought-related disasters: A global reassessment. The Journal of Environment \& Development, 16(3), 328-344, 2007

[6] Wilhite, D. A. Drought as a natural hazard: concepts and definitions, 2000

[7] Shiau, J. T., Feng, S., \& Nadarajah, S. Assessment of hydrological droughts for the Yellow River, China, using copulas. Hydrological Processes: An International Journal, 21(16), 2157-2163, 2007

[8] Mishra, A. K., \& Singh, V. P. A review of drought concepts. Journal of hydrology, 391(1-2), 202-216, 2010

[9] Kogan, F. N. Droughts of the late 1980s in the United States as derived from NOAA polar-orbiting satellite data. Bulletin of the American Meteorological Society, 76(5), 655-668, 1995

[10] Guttman, N. B. Accepting the standardized precipitation index: a calculation algorithm 1. JAWRA Journal of the American Water Resources Association, 35(2), 311-322, 1999

[11] Guttman, N. B. Comparing the palmer drought index and the standardized precipitation index 1. JAWRA Journal of the American Water Resources Association, 34(1), 113-121, 1998

[12] Ray, K. S., \& Shewale, M. P. Probability of occurrence of drought in various sub-divisions of India. Mausam, 52(3), 541-546, 2001

[13] Efstathiou, M. N., \& Varotsos, C. A. Intrinsic properties of Sahel precipitation anomalies and rainfall. Theoretical and applied climatology, 109(3-4), 627633, 2012

[14] McKee, T. B. Drought monitoring with multiple time scales. In Proceedings of 9th Conference on Applied Climatology, Boston, 1995, 1995

[15] Eris, E., Aksoy, H., Onoz, B., Cetin, M., Yuce, M. I., Selek, B., ... \& Karakus, E. U. Frequency analysis of low flows in intermittent and non-intermittent rivers from hydrological basins in Turkey. Water Supply, 19(1), 30-39, 2019

[16] Du, J., Fang, J., Xu, W., \& Shi, P. Analysis of dry/wet conditions using the standardized precipitation index and its potential usefulness for drought/flood monitoring in Hunan Province, China. Stochastic environmental research and risk assessment, 27(2), 377-387, 2013

[17] Çetin, M., Aksoy, H., Önöz, B., Eriş, E., İshak, M., Yüce, B. S., ... \& Orta, S. Deriving Accumulated Precipitation Deficits from Drought Severity-DurationFrequency Curves: A Case Study in Adana Province, Turkey. SCIENTIFIC COMMITTEE-BILLIM KURULU, 39, 2018

[18] Aksoy, H., Onoz, B., Cetin, M., Yuce, M. I., Eris, E., Selek, B., ... \& Cavus, Y. SPI-based drought severityduration-frequency analysis. In Proceedings of the 13th International Congress on Advances in Civil Engineering, Izmır, Turkey (pp. 12-14), September 2018

[19] Tsakiris, G., Kordalis, N., Tigkas, D., Tsakiris, V., \& Vangelis, H. Analysing drought severity and areal extent by 2D Archimedean copulas. Water Resources Management, 30(15), 5723-5735, 2016

[20] Shiau, J. T. Fitting drought duration and severity with two-dimensional copulas. Water resources management, 20(5), 795-815, 2006

[21] Cancelliere, A., \& Salas, J. D. Drought length properties for periodic-stochastic hydrologic data. Water resources research, 40(2), 2004 
[22] Song, S., \& Singh, V. P. Frequency analysis of droughts using the Plackett copula and parameter estimation by genetic algorithm. Stochastic Environmental Research and Risk Assessment, 24(5), 783-805, 2010

[23] Salvadori, G., De Michele, C., Kottegoda, N. T., \& Rosso, R. Extremes in nature: an approach using copulas (Vol. 56). Springer Science \& Business Media, 2007 [24] Kuhn, G., Khan, S., Ganguly, A. R., \& Branstetter, M. L. Geospatial-temporal dependence among weekly precipitation extremes with applications to observations and climate model simulations in South America. Advances in Water Resources, 30(12), 2401-2423, 2007

[25] Nelsen, R. B. An introduction to copulas. Springer Science \& Business Media, 2007

[26] Mirakbari, M., Ganji, A., \& Fallah, S. R. Regional bivariate frequency analysis of meteorological droughts. Journal of Hydrologic Engineering, 15(12), 9851000,2010

[27] Tosunoglu, F., \& Can, I. Application of copulas for regional bivariate frequency analysis of meteorological droughts in Turkey. Natural Hazards, 82(3), 1457-1477, 2016

[28] Shiau, J. T., \& Modarres, R. Copula-based drought severity-duration-frequency analysis in Iran. Meteorological Applications: A journal of forecasting, practical applications, training techniques and modelling, 16(4), 481489, 2009

[29] Lee, T., Modarres, R., \& Ouarda, T. B. Data-based analysis of bivariate copula tail dependence for drought duration and severity. Hydrological Processes, 27(10), 1454-1463, 2013

[30] Yusof, F., Hui-Mean, F., Suhaila, J., \& Yusof, Z. Characterization of drought properties with bivariate copula analysis. Water resources management, 27(12), 4183-4207, 2013

[31] Sklar, A., SKLAR, A., \& Sklar, C. A. Fonctions de reprtition an dimensions et leursmarges, 1959

[32] Salvadori, G., \& De Michele, C. Frequency analysis via copulas: Theoretical aspects and applications to hydrological events. Water resources research, 40(12), 2004

[33] Poulin, A., Huard, D., Favre, A. C., \& Pugin, S. Importance of tail dependence in bivariate frequency analysis. Journal of Hydrologic Engineering, 12(4), 394403, 2007 